\title{
López Portillo y Carazo Odio: el apoyo al sandinismo. 1976-1979
}

Hugo Martínez - Acosta

Estudiante de Doctorado

Universidad Nacional Autónoma

México

\section{Resumen}

En este artículo abordo la política que desarrolló el gobierno de México en torno a la revolución nicaragüense durante los primeros años de la presidencia de José López Portillo; asimismo, las coincidencias entre el mandatario mexicano y su homólogo costarricense Rodrigo Carazo Odio, quien, brindó un apoyo abierto a la lucha del Frente Sandinista de Liberación Nacional en contra de Anastasio Somoza Debayle. Dicha simpatía del Sr. Carazo la logró transmitir a López Portillo, quien se

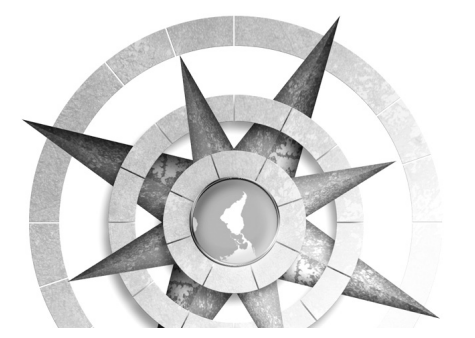

http://dx.doi.org/10.15359/tdna.33-e.9 convirtió en un partidario de la lucha sandinista, apoyando a dicho movimiento revolucionario en diversas formas.

Palabras claves: política internacional de México; Revolución nicaragüense, José López Portillo, Rodrigo Carazo Odio, Temas de Nuestra América, Cátedra del Exilio.

\begin{abstract}
This article I approaches the Mexican policy in regard to the Nicaraguan revolution during the first years of José López Portillo's presidency. It also analyzes the meeting points between López Portillo and his Costa Rican counterpart, Rodrigo Carazo Odio, who provided open support for the struggle of the Sandinista National Liberation Front against Anastasio Somoza Debayle, in Nicaragua. Mr. Carazo managed to convey that empathty to Lopez Portillo who became a supporter of the
\end{abstract} Sandinista revolutionary struggle in various ways. 
Keywords: Mexican Internacional Policy; Nicaraguan Revolution; José López-Portillo; Rodrigo Carazo-Odio; Temas de Nuestra América, Exile Research Group

Este texto es un avance de la tesis doctoral que se presentará en próximas fechas. En él abordo la política que desarrolló el gobierno de México en torno a la revolución nicaragüense durante los primeros años de la presidencia de José López Portillo, la cual se basó en la importancia que alcanzó el país gracias a los importantes hallazgos petroleros en el golfo de México que lo colocaron como un importante productor mundial de hidrocarburos y, por ende, en un actor internacional. Igualmente abordo las coincidencias que tuvieron el mandatario mexicano y su homólogo costarricense Rodrigo Carazo Odio, quien, por otra parte, había brindado un apoyo abierto a la lucha del Frente Sandinista de Liberación Nacional en contra de Anastasio Somoza Debayle, simpatía que logró transmitir a López Portillo, quien, a su vez, se convirtió en un partidario de la lucha sandinista, apoyando a dicho movimiento revolucionario en diversas formas, y al mismo tiempo, brindando, a través del aparato diplomático mexicano apostado en la zona, ayuda a los exiliados nicaragüenses que se vieron obligados a dejar su país por la violencia ge- neralizada en contra de todo aquel que fuera mínimamente sospechoso de estar con el sandinismo.

\section{Algunas consideraciones}

Se habla de exilio cuando un individuo o un grupo de ellos deben abandonar el territorio que les vio nacer o en el que han vivido por algún tiempo. Las razones para dejar su habitual residencia pueden ser variadas, pero casi siempre son por motivos políticos que ponen en peligro la vida o integridad física de la persona o de la comunidad. En el ámbito internacional el exilio es una figura jurídica que no existe; en cambio el refugio y el asilo son las dos instituciones que han sido reguladas en el derecho internacional: el primero, en el ámbito de las Naciones Unidas; y el segundo ha recibido un tratamiento mayor en el contexto interamericano.

Es importante tener en cuenta dicha precisión, pues México no prestó atención a la figura del refugio durante casi todo el siglo XX, no así a la del asilo, que fue la que reguló la entrada de ciudadanos extranjeros al país, que por diversas razones debieron encontrar en territorio mexicano protección a la persecución que ponía en peligro su vida, su libertad y su integridad física. Sin embargo, así como se precisó lo anterior, debe mencionarse que las
178 López Portillo y Carazo Odio: el apoyo al sandinismo. 1976-1979

Hugo Martínez Acosta

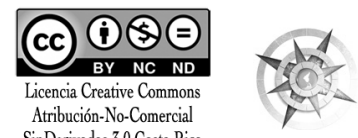

SinDerivadas 3.0 Costa Rica 
personas no siempre entraron bajo las figuras antes referidas, pues, ante la necesidad de poner a salvo la vida, no pocas entraron por sus propios medios, apoyadas por algún familiar, amigo u organismo que estuviera dispuesto a otorgarles ayuda, con lo que se constituyó el exilio. ${ }^{1}$

\section{López Portillo. La diplomacia petrolera y el compromiso revolucionario}

En medio de la crisis económica más severa que hubiese experimentado el país, y después de unas elecciones en las que José López Portillo fue el único candidato, éste fue nombrado presidente de México en 1976. El nuevo gobierno heredó una abultada deuda externa que tuvo efectos políticos, pues la población perdió confianza en el gobierno debido al bajo nivel de vida, producto de la misma crisis.

Desde el inicio de su administración en materia de política exterior, López Portillo estableció la necesidad de basar esta política en principios jurídicos de igual-

1 Un análisis cuidadoso de la diferencia entre las figuras del asilo y de refugio se encuentra en la obra de Guadalupe Rodríguez de Ita "Un México protector... de asilados y refugiados durante la guerra fría. Entre la definición y la ambigüedad" en, Dimensión Antropológica, México, INAH, año 15. vol. 43. mayo-agosto de 2008, pp.121-158. dad entre los Estados, salvaguardando la soberanía nacional. ${ }^{2}$ La difícil situación del país ocasionada por la crisis económica dio un vuelco inesperado cuando se afirmó que había yacimientos petroleros en la Sonda de Campeche, con lo cual comenzó la extracción y producción de grandes cantidades de petróleo. ${ }^{3}$ La confirmación de la existencia de súper pozos petroleros en la Sonda de Campeche ofreció al gobierno mexicano la oportunidad de reiniciar la política exterior activa que había empezado Luis Echeverría años atrás, aunque con mar-

2 "La política exterior de México, según el discurso que pronunció el C. Lic. José López Portillo al asumir el cargo de presidente constitucional de los Estados Unidos Mexicanos el 10 de diciembre de 1976", en Informe de Labores 10 de septiembre de 1976 al 31 de agosto de 1977, México, Secretaría de Relaciones Exteriores (en adelante sre), 1977, p. 15. Cfr. "Las relaciones exteriores de México en el primer informe del C. Presidente de la República, Lic. José López Portillo. Del 1o de septiembre de 1977" en, Informe de labores 10 de septiembre de 1976 al 31 de agosto de 1977, México, SRE, 1977, p. 17.

3 El descubrimiento en la Sonda de Campeche de los campos petroleros marinos Akal, Chac y Kutz que forman el activo "Cantarell", llamado así porque un pescador campechano de nombre Rudesindo Cantarell encontró en su trabajo diario una gran mancha de aceite que provenía del fondo del mar y lo reportó a funcionarios de Petróleos Mexicanos. El incidente ocurrió en 1971, y ofreció al país la enorme posibilidad de volverse una potencia petrolera internacional. Entre 1974 y 1981 se logró la autosuficiencia productiva; se frenó la importación de productos petroleros y se reactivó la exportación de crudo y sus derivados. pemex 70 años. Relato iconográfico, México, Petróleos Mexicanos, México, 2008. p. 118. Cfr. Joel Álvarez de la Borda, Crónica del petróleo en México. De 1863 a nuestros días, México, Archivo Histórico de pemex, 2006. p. 118. 
cadas diferencias. A partir de ese suceso, el gobierno mexicano pasó de una política exterior activa en el discurso a una efectiva en los hechos. ${ }^{4}$ México ocupó un lugar destacado en las discusiones internacionales en torno al desarrollo económico, los derechos humanos, el desarme y el derecho del mar. Hacia 1980 el país participó en el Consejo de Seguridad de la Organización de las Naciones Unidas (ONU), lo cual no había hecho desde $1946 .{ }^{5}$

\section{López Portillo. Con Nicaragua... y con la revolución}

Hacia finales de 1978, el gobierno mexicano estaba decidido a darle al país un papel más activo en el escenario internacional. Ya convertido en una potencia petrolera y en medio de una crisis mundial de hidrocarburos, México logró una estatura internacional que le permitió ser un protagonista en la política internacional; únicamente faltaba la coyuntura que le ofreciera la oportunidad de actuar en esa dirección, la cual se presentó con la revolución sandinista en Nicaragua y la crisis generalizada de Centroamérica.

4 Mónica Toussaint, Mario Vázquez, Manuel Ángel Castillo, Historia de las relaciones internacionales de México, 1821-2010., t 2. Centroamérica, México, Secretaría de Relaciones Exteriores (sre), 2011, p. 136.

5 Mario Ojeda Gómez, México: El surgimiento de una política exterior activa, México, sep, 1986, pp. 154 y 155.
Desde los años sesenta, estaban presentes en Nicaragua grupos armados, que no representaban una amenaza al dominio de los Somoza en el país. Sin embargo, hacia 1977, luego de superar diferencias que los habían dividido por años, el Frente Sandinista de Liberación Nacional (FSLN) logró convencer al clero reformista, a intelectuales y a empresarios desencantados de la corrupción gubernamental de que sólo a través de una rebelión armada se podría instaurar la democracia en el país. Al mismo tiempo de que amalgamaron a diversos sectores nicaragüenses obtuvieron el apoyo de tres líderes regionales: el presidente venezolano Carlos Andrés Pérez -quien los dotó de recursos financieros-, el general Omar Torrijos -mandatario de Panamá, quien también les proporcionó diversos apoyos- y Rodrigo Carazo Odio -cuyo gobierno ofreció apoyo político y logístico, además de que había brindado su territorio para a un gobierno sandinista en el exilio y un santuario seguro para la guerrilla del frente revolucionario del sur. ${ }^{6}$

En septiembre de 1978, el gobierno de Estados Unidos convocó a una reunión

6 Ibid., p. 138.; Cfr. También a René Herrera y Mario Ojeda, "La política de México en la región de Centroamérica”, en Foro Internacional, núm., 91, abril-junio de 1983. p. 432.
180 López Portillo y Carazo Odio: el apoyo al sandinismo. 1976-1979

Hugo Martínez Acosta

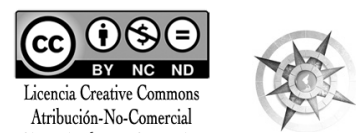

SinDerivadas 3.0 Costa Rica 
de la Organizaciones de los Estados Americanos (OEA) con el propósito de examinar la situación en Nicaragua. El interés real del gobierno estadounidense era utilizar al organismo interamericano para formar un equipo de mediación que permitiera la salida de Somoza, pero que se preservara el statu quo en Nicaragua, continuando con el apoyo a la Guardia Nacional. Ante ello, México, en voz del secretario de Relaciones Exteriores Jorge Castañeda y Álvarez de la Rosa declaró que no aprobaría ni participaría en ningún intento de utilizar a la OEA para intervenir en Nicaragua, pues sólo al pueblo nicaragüense le correspondería decidir su futuro. ${ }^{7} \mathrm{La}$ propuesta de gobierno de James Carter fracasó hacia finales del año.

Al empezar el año de 1979, la situación en Nicaragua continuó agravándose aún más. La Guardia Nacional somocista aumentó la represión en contra de la población nicaragüense, de forma cada vez más brutal. Por otra parte, el gobierno estadounidense, convencido de que Somoza era ya una figura indefendible, optó por dejarlo solo. En tanto esto sucedía, López Portillo, con la convicción de que México debía jugar un papel más activo en la política internacional,

7 Guillermo Garcés Contreras, México. Cincuenta años de política internacional, México, Instituto de Capacitación Política-Partido Revolucionario Institucional, 1982, pp. 304 y 305. decidió encaminar al país en esa dirección y aprovechó la situación en Nicaragua para montar a México en el escenario internacional, por lo que de manera sorpresiva el 20 de mayo, por conducto del canciller Castañeda, se anunció la decisión del gobierno mexicano de romper relaciones diplomáticas con el gobierno de Somoza.

Esta decisión no se debió únicamente al deseo del presidente López Portillo de que México tuviera un papel protagónico en la política internacional; son varios los factores que deben ser tomados en cuenta para comprender las razones de dicha acción. Primeramente, está el hecho de que la revolución sandinista contaba con un amplio apoyo social de diversos sectores nicaragüenses, así como la antipatía generalizada de la comunidad internacional al régimen somocista, producto de una dictadura familiar que llevaba décadas en el poder.

Los factores que orillaron a México a romper relaciones diplomáticas con el régimen de Anastasio Somoza, tienen, a su vez, causas que propiciaron este hecho. Como ya se mencionó, hasta antes del rompimiento entre México y Nicaragua habían sido los gobiernos de Panamá, Costa Rica y Venezuela los que de una u otra manera habían apoyado a los sandinistas. Sin embargo, el peso 
económico recaía en las arcas del gobierno venezolano de Carlos Andrés Pérez; en marzo de 1979, Andrés Pérez dejó la presidencia en manos de Luis Herrera Campins, quien provenía del Comité de Organización Política Electoral Independiente (COPEI) de tendencia demócrata-cristiana. Esta situación hizo pensar que el nuevo gobierno venezolano ya no continuaría otorgando el apoyo económico a los sandinistas, -lo que ponía en riesgo el resultado de su revolución-, quienes quizás -se pensó-, acudirían a Cuba para suplir el apoyo que Venezuela ya no les proporcionaría, pero una participación mayor del régimen de Castro hacía temer una intervención abierta del gobierno estadounidense en la región. Ante ello, se desvió la mirada a México, el otro país con la capacidad de soportar el peso financiero. ${ }^{8}$

Con el propósito de lograr el apoyo de México para la causa sandinista, el presidente costarricense Rodrigo Carazo Odio viajó para México a entrevistarse con el mandatario mexicano. El encuentro tuvo lugar el 20 de mayo en Cozumel, Quintana Roo. Carazo Odio expuso la gravedad de lo que ocurría en Nicaragua, y, tras la conversación, el presidente mexicano tomó la decisión de romper con ese país. Al respecto,

8 M. Ojeda Gómez, México: El surgimiento..., op. cit. p. 138.
López Portillo relata en sus memorias tituladas Mis Tiempos, que desde el 17 de enero de 1979 pasado, el canciller panameño le llevó un recado de Omar Torrijos y Carlos Andrés Pérez para que México encabezara un movimiento formal para derrocar a Somoza, y que ellos estaban dando armas y apoyo a los sandinistas. López Portillo señala que "Con toda consideración les dije que no íbamos a sacrificar un principio fundamental, el de no intervención [...] Que Somoza era el 'Frankensteinito' de los E.U.A.", que si ahora ellos no sabían cómo sacarlo y sustituirlo, que lo hicieran ellos directamente.

Yo tenía ya resuelta la ruptura de relaciones y buscaba la oportunidad más útil para hacerlo; la información personal, amplia y directa que me dio Carazo Odio, Presidente de Costa Rica, sobre la situación en Nicaragua, fortaleció esa resolución. La represión genocida y sin destino de Somoza, abandonado por su socio norteamericano y sólo mantenido por sus sicarios, hacía estéril la lucha del pueblo. Además, de algún modo, tenía en mente el compromiso moral con un grupo conmovedor de jóvenes nicaragüenses que, de

182 López Portillo y Carazo Odio: el apoyo al sandinismo. 
la Secundaria, se había ido a la guerrilla y aspiraba a formar un Gobierno de dignidad nacional, democrático y plural. ${ }^{9}$

Actor fundamental de lo que sucedió en Nicaragua durante estos años fue el embajador Gustavo Iruegas, cuyo testimonio fue recogido por la doctora Mónica Toussaint: ${ }^{10}$ Iruegas nos cuenta que en entrevista que tuvo con el presidente mexicano éste le inquirió:

¿¿Qué pasa en Nicaragua?

- Pues hay una guerra civil, respondió Irueguas.

- ¿Tanto así?, volvió a preguntar López Portillo.

-Señor, hay una guerra civil.

¿Y qué se supone que va a pasar?

Estoy de acuerdo en romper relaciones, pero ¿cuándo?

Yo no estaba preparado para contestar eso, pero le respondí: Va a haber un paro patronal pronto, yo creo que debe ser coincidente.

9 http://www.memoriapoliticademexico.org/Efemerides/5/20051979.html (Consultado el 01 de Octubre de 2016).

10 Mónica Toussaint, Diplomacia en tiempos de guerra. Memorias del embajador Gustavo Iruegas, México. Instituto de Investigaciones Dr. José María Luis Mora UNAM-CIALC - La Jornada Ediciones, 2013. p. 207.
López Portillo concluyó diciendo: "Usted mándenos decir".

Yo me fui, regresé a Managua, hablé con los sandinistas, les dijimos lo que queríamos hacer y se pusieron felices. En Managua siguieron los acontecimientos muy cerca de la guerra. Entonces pensé, tengo que volver a hablar con mis amigos. Y me fui a buscar a Daniel Ortega a Costa Rica, clandestino yo, clandestino él. Ellos querían que la ruptura coincidiera con la ofensiva final y yo insistí que no, que teníamos que darnos un tiempo a fin de que la ruptura tuviera efectos, pues la noticia de la ofensiva ahogaría a la de la ruptura.

Cabe señalar que el gobierno mexicano, antes de anunciar el rompimiento diplomático con el régimen somocista, consultó a otros involucrados para evitar posibles interpretaciones equivocadas. Entre los consultados estaba el gobierno cubano, cuyo presidente se trasladó a Cozumel tres días antes de la visita de Carazo Odio para entrevistarse con López Portillo. ${ }^{11}$

La ruptura de las relaciones diplomáticas entre México y Nicaragua marca asimismo un quiebre en la política exterior de México al apartarse de uno de

11 Ibid., pp.. 138 y139. 
sus principales ejes de actuación, que era el principio de no intervención, pues al utilizar el argumento de que el régimen de Somoza violaba en forma sistemática los derechos humanos del pueblo nicaragüense, lo que constituía en sí mismo un genocidio, el gobierno mexicano estaba calificando acciones de otro gobierno, lo cual lo apartaba de su tradicional actitud de no evaluar acciones de otras naciones. ${ }^{12}$

Una vez rotos los lazos diplomáticos entre México y Nicaragua, el gobierno de López Portillo se dio a la tarea de tratar de convencer a otras naciones de América Latina en favor de la causa sandinista, sin mucho éxito. Igualmente bloqueó una iniciativa estadounidense presentada en junio de 1979 en la OEA, para que se constituyera una fuerza interamericana que restableciera el orden y que asegurase elecciones democráticas en Nicaragua. Finalmente, el 19 de julio de ese mismo año la revolución sandinista triunfó, dos días después de que Anastasio Somoza huyera del país y buscara refugio en la capital paraguaya. ${ }^{13}$

12 Jorge Chabat, "Condicionantes del activismo de la política exterior mexicana (1960-1985)”, en Humberto Garza Elizondo (comp.), Fundamentos y prioridades de la politica exterior de México, México, El Colegio de México, 1986 p. 101 y 102. Mario Ojeda Gómez, México: El surgimiento..., p. 137.

13 M. Ojeda Gómez, México: El surgimiento..., p. 140.

\section{Carazo Odio y el apoyo al sandinismo}

Por su parte, el gobierno de Rodrigo Carazo Odio (8 de mayo de 1978 a 8 de mayo de1982) había permitido que su territorio sirviera para establecer campamentos de FSLN, y que otros actores en territorio costarricense tuvieran un espacio para realizar actividades que sirvieran para terminar con el régimen somocista. Hacia septiembre de 1978, la embajadora de México en Costa Rica Pilar Saldívar y Fernández del Valle informó a la cancillería mexicana que Carlos Tunnerman, acompañado de otros dos miembros del llamado Grupo de los 12; se encontraba en Costa Rica para solicitar apoyo a su demanda tanto de dicho país como del ámbito Internacional. ${ }^{14}$

En el extenso telegrama enviado por la representante mexicana, ésta informó también que el gobierno costarricense se hallaba muy preocupado por un posible éxodo masivo de nicaragüenses hacia su país, debido al recrudecimiento de la violencia en Nicaragua, por lo que había movilizado a elementos de la Guardia Civil a dos kilómetros de la frontera y alertado a la Cruz Roja costarricense en la ciudad fronteriza de Liberia a fin de poder atender lo conducente pues calculaba que podrían llegar a su país hasta 100 mil nicaragüenses.

14 Telegrama núm., 160, Embamex Costa Rica a SRE. AHGE-SRE., exp. III-6223-16 (1ª parte).
184 López Portillo y Carazo Odio: el apoyo al sandinismo. 1976-1979

Hugo Martínez Acosta

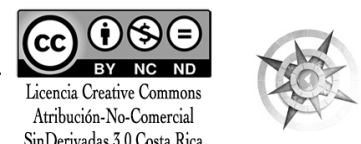


En el mismo telegrama, la representante mexicana indicó a la cancillería que el presidente costarricense se había dirigido a todos los ciudadanos centroamericanos, en el que abogó para que en $\mathrm{Ni}$ caragua se pudiera encontrar pronto la paz, y explicó que la presencia de aviones y helicópteros provenientes de Venezuela y de Panamá obedecía a que su gobierno ya no podía seguir tolerando que los civiles continuaran sufriendo ataques de la Guardia Nacional nicaragüense, cuyas tropas habían penetrado a mediados de septiembre a territorio de Costa Rica teniendo como resultado diez heridos. ${ }^{15}$ Ante la protesta que su gobierno envió al de Nicaragua, éste respondió que debido a que elementos del Frente Sandinista de Liberación Nacional utilizaban el territorio de Costa Rica para lanzar ataques en contra de Nicaragua, la Guardia Nacional había desplegado elementos que les combatieron, huyendo hacia territorio de dicho país. ${ }^{16}$

En septiembre del mismo año, el embajador de México en Nicaragua, Gustavo Iruegas, informó a la Cancillería mexicana que, ante la propuesta de que hiciera el gobierno costarricense a las demás naciones centroamericanas de mediar en el conflicto nicaragüense,

15 Telegrama núm., 677. Embamex Costa Rica a SRE. AHGE-SRE., exp. III-6224-1 (2a parte).

16 Telegrama núm.. 335. Embamex Nicaragua a SRE. AHGE-SRE., exp. III-6223-16 (1 ${ }^{\text {a }}$ parte).
Anastasio Somoza expresó en rueda de prensa que "su gobierno podía utilizar los servicios de un amigable componedor pero no un mediador cuando la lucha es de un gobierno constituido contra rebeldes, así lo comprendieron los presidentes de Centroamérica y se negaron a asistir a una entrevista cumbre" ${ }^{17}$ La respuesta que ofreció en México la recién acreditada embajadora de Costa Rica en la capital mexicana, María del Rosario Fournier de Calderón Guardia, ante lo expresado por el mandatario nicaragüense fue que su país era, como México, respetuoso del principio de no intervención, sumando a la declaratoria que no pensaba que su país fuera a ser atacado por fuerzas externas. ${ }^{18}$

\section{López Portillo y el apoyo a los asilados}

Hacia la segunda mitad de la década de los setenta, el número de solicitudes de asilo presentadas a la Embajada de México en Nicaragua se intensificó conforme fue escalando la actividad militar del sandinismo en contra del régimen somocista y la represión del mismo, llegando a ser de cientos hacia 1978, el cual no se detuvo hasta que fue derrocado Somoza en junio de 1979.

\footnotetext{
17 Idem.

18 "Costa Rica: no intervención en Nicaragua”, en La tarde de Guatemala, 12 de septiembre de 1978. AHGE-SRE. III-6223-16 (1 ${ }^{\text {a }}$ parte).
} 
Una peculiaridad de las solicitudes que fueron recibidas mientras se recrudecía la represión somocista fue que no sólo eran de presuntos combatientes y simpatizantes del FSLN, sino también de personas que, con la sola sospecha de que un familiar era miembro del sandinismo, los acusaban y los conducían a los cuarteles de la Guardia Nacional. Por ello y ante el temor de caer en las mazmorras somocistas, no pocas mujeres con sus hijos, así como ancianos solicitaron asilo. Asimismo, esas solicitudes se sumaron las de personas en deplorable estado de salud, como fue el caso de Manuel Salvador González Ríos, quién llegó a la Embajada con ambas manos amputadas; o de varias mujeres que, una vez en territorio mexicano debieron ser internadas en hospitales para curarlas de las violaciones de las que habían sido víctimas por parte de miembros de la Guardia Nacional. También hubo hombres que fueron internados en hospitales siquiátricos. ${ }^{19}$

En diciembre de 1978, la Embajada de México en Nicaragua reportó a la Cancillería que en dicha representación se encontraban 113 nicaragüenses en espera de recibir los salvoconductos que les permitieran dirigirse a México, los cua-

19 Telegrama núm. 008, Embamex Nicaragua a sre, 9 de enero de 1979. ahge-sre, exp. III-5869-1 (3a parte). les se podían retrasar por semanas o meses. ${ }^{20}$ Igualmente reportó que durante el referido año había otorgado asilo a un total de 334 personas, asegurando que a lo largo del mismo año habían logrado trasladar a 237 de ellos a México. ${ }^{21} \mathrm{Se}$ gún testimonios del embajador Gustavo Iruegas recogidos por Mónica Toussaint, cuando se tenía un promedio de 40 o 50 asilados en la Embajada, el gobierno mexicano le enviaba un avión de la Fuerza Aérea Mexicana (El Quetzalcoatl) para trasladar a los asilados y llevarles al mismo tiempo alimentos y medicinas que eran empleados en la representación para beneficio de los asilados. ${ }^{22}$

Como ya se mencionó, el 20 de mayo de 1979 el gobierno mexicano rompió relaciones diplomáticas con el de Nicaragua, lo cual provocó que los asuntos de México en el país quedaran en manos de Perú; la representación de ese país debía tramitar los salvoconductos de los asilados que permanecieron en la Embajada mexicana; sin embargo, el embajador de ese país, temeroso, no se atrevía a presionar a las autoridades nicaragüenses para que eso sucediera.

20 "Lista de personas asiladas en la Embajada de México en Nicaragua que se encuentran en espera de salvoconductos, 22 de diciembre de 1978". ahge-sre, exp. III-5869-1 (3a Pte).

21 "Constancia para el expediente". 26 de enero de 1979. ahge-sre exp. III-5869-1 (3a parte).

22 M. Toussaint, Diplomacia en tiempos de guerra..., pp. 200 y 201.
186 López Portillo y Carazo Odio: el apoyo al sandinismo. 1976-1979

Hugo Martínez Acosta

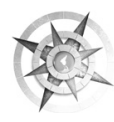


No fue sino hasta que el embajador Iruegas le presionó, externándole que al siguiente día del rompimiento de relaciones diplomáticas llegaría un avión proveniente de México, y que en todo caso si no estaban los salvoconductos, le dejaría a los asilados. Esto provocó que el representante peruano obtuviera los salvoconductos. ${ }^{23}$

\section{Los caminos nos llevan a Costa Rica}

El gobierno de Rodrigo Carazo Odio había permitido que el territorio de Costa Rica sirviera para establecer campamentos del FSLN, y que otros actores no identificados con el sandinismo utilizaran ese territorio costarricense para buscar apoyo para a el gobierno de Anastasio Somoza Debayle. Asimismo, y ante el recrudecimiento de las acciones de la Guardia Nacional contra los nicaragüenses en 1979 y ante las claras acciones del gobierno somocista por retrasar durante semanas o meses, e incluso negar los salvocunductos que permitieran llevar a México a los asilados, no pocos nicaragüenses se trasladaron a Costa Rica para solicitar al gobierno mexicano asilo político, a lo que se accedió, llevándolos a territorio mexicano, en donde se les extendió la categoría de "asilado político". Cabe mencionar que

23 Ibid. p. 209. el avión Quetzalcóatl, en sus constantes vuelos a Managua, frecuentemente aterrizaba primero en Costa Rica, para después partir hacia Nicaragua.

Pero no sólo para eso se utilizó el territorio de Costa Rica. Según testimonios que ha rescatado Fabián Campos Hernández de funcionarios mexicanos acreditados en las representaciones de Nicaragua, éstos comentaron que cuando el avión de la Fuerza Aérea enviado desde México para recoger a los asilados en Managua hacía escala antes en Costa Rica, en donde se otorgaban distintos recursos a los miembros del Frente Sandinista. Lo anterior no hubiera sido posible de no contar con el apoyo y venia del gobierno de Carazo Odio. ${ }^{24}$

\section{Conclusiones}

Como puede apreciarse, el gobierno de José López Portillo, resuelto a que México tuviera una participación dinámica en la política internacional, basado en el poder que le daban los importantes hallazgos petroleros en el

24 Con la generosidad que caracteriza a Fabián Campos Hernández, este me ha compartido algunas de sus entrevistas y que ya pronto saldrán publicadas. Fabián Campos Hernández “QQuién me quita lo bailado? Entrevista a Enrique Camacho Vaca, agregado cultural de México en Nicaragua, 1974-1984”, en Mario Vázquez, Fabián Campos (coords.), México ante el conflicto centroamericano. Testimonio de una época, México, UNAM-CIALC/ Bonilla Artiga Editores, 2017, pp. 89-108. 
golfo de México, que lo situaban como un jugador importante en el escenario internacional, decidió tomar parte activa en el conflicto en Nicaragua, inclinándose por apoyar al Frente Sandinista de Liberación Nacional. Dicho apoyo no hubiera sido factible de no haber sido por la trascendente labor de convencimiento que para ello realizó el presidente costarricense Rodrigo Carazo Odio, quien, aparte de facilitar el territorio de su país para el establecimiento de un gobierno sandinista en el exilio y el asentamiento de campamentos del sandinismo que resultaron ser vitales para las actividades del Frente Sur, se dio a la tarea de buscar el auxilio del gobierno mexicano a la causa revolucionaria del FSLN, pues, si bien su gobierno había prestado auxilio, no le hubiera sido capaz de soportar el peso financiero, como sí lo podía hacer México. ${ }^{25}$

Por otra parte, se puede apreciar que el gobierno de José López Portillo no solo brindó apoyo al FSLN pues, fiel a su tradición de dar asilo, se convirtió en un importante destino para quienes buscaron preservar su vida al convertirse México en refugio para cientos de nicaragüenses que debieron dejar su país por la represión ejercida por el régimen de Anastasio Somoza Debayle, que no reparó en reprimir a todo aquel sospechoso mínimamente de estar a favor de la causa sandinista. Para ello, López Portillo se valió del aparato diplomático mexicano apostado en la zona, que a su vez se convirtió en importante aliado de la causa sandinista.

$25 \mathrm{Al}$ respecto del apoyo que desde Costa Rica se dio a la causa sandinista, se encuentra el trabajo de José Picado Lagos, quien brindó a la tarea de recoger los testimonios de distintos costarricenses que combatieron contra la dictadura somocista. José Picado Lagos (comp.), Los amigos venían del sur, San José de Costa Rica, Editorial Universidad Estatal a Distancia, 2013.

188 López Portillo y Carazo Odio: el apoyo al sandinismo. 1976-1979 